\title{
Feasibility of Using the Clamp Meter in Measuring X-Ray Tube Current
}

\author{
Sung-chul Kim \\ Department of Radiological science \\ Gachon University Medical campus, Incheon, 406/799, Rep. of Korea
}

\begin{abstract}
The clamp meter maintains electric safety as a non-invasive method while measuring the absolute value of tube current with it has been recently developed for an X-ray high-tension cable. Especially this can show high accuracy at short X-ray exposure time. Considering such a condition, this study is to evaluate the feasibility of a clamp meter in measuring X-ray tube current by taking the measurements and comparing with those of the Dynalyzer III which has been considered as a standard measuring device. From measuring the tube current accuracy depending on changes in tube voltage and exposure time, the clamp meter showed higher accuracy rate which was $-1.3 \sim 4.2 \%$ difference. Thus clamp meter can be used for clinical radiologists who are not familiar electric circuit to manage $X$-ray devices easily and correctly in the future.
\end{abstract}

Keywords: X-ray tube current, Clamp meter, Non-invasive method, X-ray tube voltage

\section{INTRODUCTION}

For initial quality control, the method used was the measurement of the size, weight and volume of materials of whole products, and compared such measured results with the quality standard to decide products' feasibility. In the 1920s, statistical quality management was developed by W.A. Shewhart of Bell Telephone Laboratories. In Korea, quality control started along with the proclamation of the Act of Standardization in 1961 [1]. Since the implementation of the regulations on diagnostic radiation safety control by the Ministry of Health and Welfare in January 1995, the systematic management of medical X-ray devices has continued until today [2]-[4].

For the performance test of diagnostic X-ray devices, various tests from the grounding system to the performance management of X-ray devices were conducted. Specifically, an accurate measurement can be conducted only through invasive meter on testing the tube voltage, tube current and timer. However, due to convenience, such measurements were all managed with a connectionless measuring system.

The measurement of the tube current is conducted by setting the initial value of the tube current as the standard and determining the ratio of the relative X-ray output dose in terms of the non-invasive measurement method. Thus, in case of having an error in the initial standard tube current value, the values of the rest are affected.

The Dynalyzer III is the most frequently used as the standard measuring device in measuring the tube current by connecting

\footnotetext{
* Corresponding author,Email : ksc@gachon.ac.kr Manuscript received Oct. 15, 2012; revised Mar 10, 2013; accepted Mar 20, 2013
}

the tube current system to the secondary neutral point of a high voltage transformer. The non-invasive method, on the other hand, is to predict the accuracy by measuring the relative depth dose of the test tube current based on the output dose value of the standard tube current. This is the most frequently used method to measure the current of a high-tension wire aside from the clamp meter.

The clamp meter maintains electric safety as a non-invasive method while measuring absolute value of tube current with it has been recently developed for an X-ray high-tension cable. Especially this can show high accuracy at short X-ray exposure time. Considering such a condition, this study is to evaluate the feasibility of a clamp meter in measuring X-ray tube current by taking the measurements and comparing with those of the Dynalyzer III which has been considered as a standard measuring device.

\section{METHODS}

The accuracy of the tube current measurement of the clamp meter was compared with that of an invasive meter used as an $\mathrm{X}$-ray test and correction device. For the clamp meter, MagicMaX current probe of PROVA Instruments Inc. was used, whereas, the Dynalyzer III (digital display: M-96320, high voltage unit: M-96311) of Radcal Co. in the U.S. was used for the invasive meter.

To increase the accuracy of the experiment, the measurement and comparison were conducted on two types: a single phase full wave rectification X-ray device most frequently used nowadays (DXG325R, Donga X-ray Co., Ltd.) and an inverter X-ray device (REX650RF, Listem Co.). 


\subsection{Tube current accuracy depending on changes in tube voltage}

The high-voltage X-ray cable was connected to the high voltage unit of the Dynalyzer III. Then, the high voltage unit and X-ray cable were connected to other high-voltage cables. The tube voltage was positioned to Anode+Cathode and the trigger was set at $75 \%$ in the single-phase device and $90 \%$ in the inverter device. At that time, delay time was set to zero for the experiment. The meter was clamped to the high-voltage cable of the X-ray while a detector to measure X-ray output is located within the exposure range of the X-ray (Figure 1 and 2).

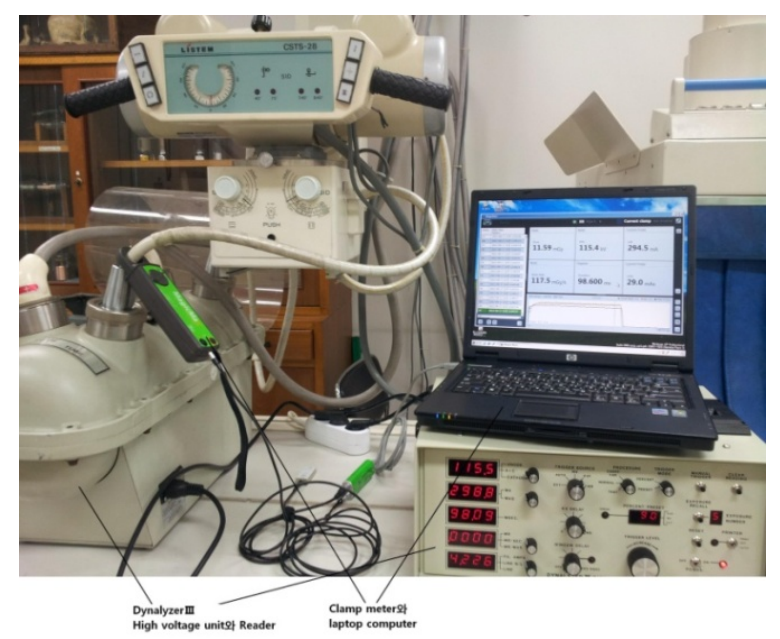

Fig. 1. Arrangement for DynalyzerIII \& clamp meter

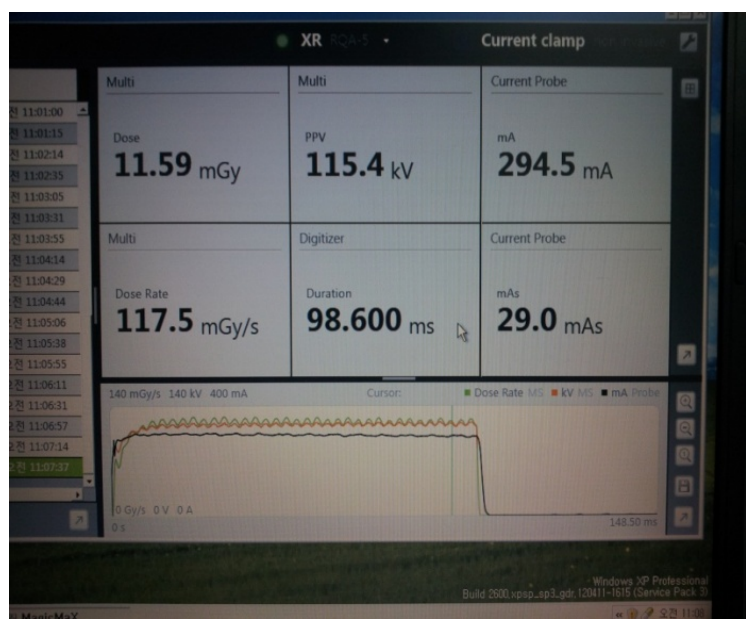

Fig. 2. Measured value \& waveform of clamp meter

Depending on rectification method of the devices, the average values were derived by measuring the tube current three times at $80 \mathrm{kV}$, the most frequently used tube voltage, and at $120 \mathrm{kV}$, which was a high tube voltage, while changing the tube current to $50 \mathrm{~mA}$ and $100 \mathrm{~mA}$ at small focus as well as $200 \mathrm{~mA}$ and $300 \mathrm{~mA}$ at large focus. At that time, the exposure time was fixed at $0.1 \mathrm{sec}$.

\subsection{Tube current accuracy depending on changes in X-ray exposure time}

Under the same experimental setting, the tube current accuracy was measured depending on changes in the X-ray exposure time. The tube voltage was fixed at $100 \mathrm{kV}$ and the tube current at $100 \mathrm{~mA}$. The inverter was controlled for time of exposure. The X-ray exposure times were changed from 10, 30, $50,100,300$, to 500 miliseconds. The accuracy of the tube current was measured.

\section{RESULT}

\subsection{Tube current accuracy depending on changes in tube voltage}

The tube current measured depending on changes in tube voltage with the clamp meter showed high concordant values with standard $\mathrm{mA}$. Values with clamp meter are $3.1 \sim 3.2 \%$ higher than those with Dynalyzer at the standard 50mA and 0.2 $\sim 0.6 \%$ higher at the standard $100 \mathrm{~mA}$ in small focused singlephase device. At high currents in the large focus, less than $1.7 \%$ differences were revealed(Table 1 ).

Table 1. Tube current accuracy in Single-phase device

\begin{tabular}{|c|c|c|c|c|}
\hline \multirow{2}{*}{$\mathrm{kV}$} & \multirow{2}{*}{$\begin{array}{c}\text { standard } \\
\mathrm{mA}\end{array}$} & \multicolumn{3}{|c|}{ measured mA } \\
\cline { 3 - 5 } & & Dynalyzer III & $\begin{array}{c}\text { clamp } \\
\text { meter }\end{array}$ & difference(\%) \\
\hline 80 & \multirow{2}{*}{50} & 45.5 & 46.9 & $1.4(103.1)$ \\
\cline { 3 - 5 } 120 & & 44.2 & 45.6 & $1.4(103.2)$ \\
\hline 80 & \multirow{2}{*}{100} & 99.8 & 100.4 & $0.5(100.6)$ \\
\cline { 4 - 5 } & & 101.7 & 101.9 & $0.3(100.2)$ \\
\hline 120 & \multirow{2}{*}{200} & 199.1 & 202.5 & $3.4(101.7)$ \\
\cline { 3 - 5 } 80 & & 187.1 & 189.9 & $2.8(101.5)$ \\
\hline 120 & \multirow{2}{*}{300} & 298.0 & 300.5 & $2.5(100.8)$ \\
\cline { 3 - 5 } 80 & & 283.3 & 286.7 & $3.4(101.2)$ \\
\hline 120 & & & &
\end{tabular}

Table 2. Tube current accuracy in Inverter system

\begin{tabular}{|c|c|c|c|c|}
\hline \multirow{2}{*}{$\mathrm{kV}$} & \multirow{2}{*}{$\begin{array}{c}\text { standard } \\
\mathrm{mA}\end{array}$} & \multicolumn{3}{|c|}{ measured $\mathrm{mA}$} \\
\hline & & Dynalyzer III & clamp meter & difference $(\%)$ \\
\hline 80 & \multirow{2}{*}{50} & 50.6 & 52.7 & $2.1(104.2)$ \\
\hline 120 & & 44.7 & 45.9 & $1.2(102.7)$ \\
\hline 80 & \multirow{2}{*}{100} & 104.5 & 104.3 & $-0.2(99.8)$ \\
\hline 120 & & 98.0 & 98.4 & $0.5(100.4)$ \\
\hline 80 & \multirow{2}{*}{200} & 211.3 & 210.2 & $-1.1(99.5)$ \\
\hline 120 & & 186.8 & 185.4 & $-1.4(99.3)$ \\
\hline 80 & \multirow{2}{*}{300} & 312.8 & 309.4 & $-3.4(98.9)$ \\
\hline 120 & & 289.4 & 285.7 & $-3.8(98.7)$ \\
\hline
\end{tabular}

In the inverter, the differences between the clamp meter and Dynalyzer was shown to be $-0.2 \sim 4.2 \%$ in the small focus and $0.5 \sim-1.3 \%$ in the large focus (Table 2). 


\subsection{Tube current accuracy depending on the changes in $X$ - ray exposure time}

When the X-ray exposure time was set at 10 miliseconds, no result was derived from both the Dynalyzer III and the clamp meter. Although the delay time of the Dynalyzer III was controlled for the experiment, it was impossible to read the measurement values. Among the measured values, 30 miliseconds was the shortest exposure time which showed $2.7 \%$ difference comparing with Dynalyzer III. The range of difference was from $-2.7 \%$ to $1.2 \%$ depending on the changes in X-ray exposure time(Table 3).

Table 3. Tube current accuracy depending on the changes in Xray exposure time

\begin{tabular}{|c|c|c|c|}
\hline \multirow{2}{*}{$\begin{array}{c}\text { standard } \\
\text { time(msec) }\end{array}$} & \multicolumn{3}{|c|}{ measured time(msec) } \\
\cline { 2 - 4 } & Dynalyzer III & clamp meter & difference(\%) \\
\hline 30 & 30.2 & 29.4 & $-0.8(97.3)$ \\
\hline 50 & 50.6 & 49.4 & $-1.2(97.6)$ \\
\hline 100 & 100.2 & 100.6 & $0.4(100.4)$ \\
\hline 300 & 311.1 & 313.5 & $2.4(100.8)$ \\
\hline 500 & 524.5 & 531.0 & $6.5(101.2)$ \\
\hline
\end{tabular}

\section{CONCLUSIVE DISCUSSION}

Since an X-ray device is harmful to the human body, continuous quality control is essential. Moreover, accuracy is important in managing the tube voltage, tube current and exposure time related to the amount of X-ray generation. However, there are many cases that measure relative value, not an absolute value, for the measurement of tube current [5], or do not measure the tube current itself [6,7]. In some studies, the measurement was made by inserting the invasive tube current system to the secondary neutral point of a high voltage transformer [8,9]. Nonetheless, it actually took much time to connect measuring point to the tube current system by opening the high-voltage transformer. Additionally, the characteristics of the measuring point in $\mathrm{AC}$ and $\mathrm{DC}$ have to be understood depending on the current type of a device [10].

A clamp meter is a measuring device that can measure the current by clamping the outer part of the electric wire without cutting the circuit of the current system. Although it has lower accuracy than the invasive method, it is effectively used for the measurement of the current in the high-voltage circuit. Recently, its accuracy has been increased by applying various methods [11-13]. Since the X-ray tube current is generated for a short period of time, unlike the general current, limitations on its use has been raised for the measurement that use a clamp meter.

Nevertheless, the accuracy of the measuring devices has been improved due to technical developments. According to this experiment on a clamp meter and invasive meter in use of the recently developed by MagicMaX current probe PROVA Instruments Inc., it showed higher accuracy in terms of the changes in the tube voltage and exposure time.
The results derived in this study are considered to be very important as these verified both efficiency and accuracy of the non-invasive device, such as the clamp meter, which has not been used for the measurement of the X-ray tube current in Korea. From now on, it is thought that clinical radiologists who do not know well enough about electric circuit may easily and correctly manage the $\mathrm{X}$-ray devices in the future.

\section{ACKNOWLEDGMENT}

"This work was supported by the Gachon University research fund of 2013."(GCU-2013-M019)

\section{REFERENCES}

[1] S.S. Kang, D.G. Kwon, and K.K. Kim, Diagnostic X-ray Equipment 2nd ed., Chung-ku Pub. co., 2011.

[2] J.M. Kim, S.C. Kim and S.G. Ko, X-ray Equipment \& Management Experiments, Daihak Pub. co., 2000.

[3] R.R. Carlton, A.M. Adler, Principles of Radiographic imaging-An art and a science 4th Ed., Thomson, 2006.

[4] T.T. Thompson, A practical Approach to Modern X-ray Equipment, Brown and co., 1978.

[5] S.S. Kang, C.S. Kim and S.J. Ko, "Usefulness of NonInvasive Measurement Tool on Performance Evaluation of Inverter Type X-ray Unit", J. of Radiological Science \& Technology, vol. 31, no. 2, 2008, pp. 123-127.

[6] B.S. Kang, K.M. Lee, W.Y. Shim, S.C. Park, H.D. Choi and Y.K. Cho, "Analyze for the Quality Control of General X-ray Systems in Capital region", J. of Radiological Science \& Technology, vol. 35, no. 2, 2012, pp. 93-102.

[7] I.C. Im, "An ability test for the use of Indirect Radiographic unit", J. of Radiological Science \& Technology, vol. 27, no. 4, 2004, pp. 37-41.

[8] J.H. Park, I.C. Im, K.R. Dong and S.S. Kang, "A Performance Evaluation of Diagnostic X-ray Unit Depends on the Hospitals Size", J. of Radiation Protection, vol. 34 no. 1, 2009, pp. 31-36.

[9] J.K. Park, "Medical Clinics'quality Management of X-ray Units in Gyeongbuk Area", J. of the Korea Contents Association, vol. 10, no. 9, 2010, pp. 267-275.

[10] P. Carter, A. Paterson, M. Thornton, A. Hyatt, A. Milne, and J. Pirrie, Chesneys' Equipment for Student Radiographers 4th Ed., Blackwell scientific Pub., 1994, pp. 64-76.

[11] J.D. Ramboz, "A Highly Accurate hand-held Clamp-on Current Transformer", IEEE trans. Instrum., vol. 45, no. 2, 1996, pp. 445-448.

[12] E. So, D.A. Bennett, "A low-current Multistage Clampon Current Transformer with Ratio errors below 50 ppm", IEEE trans. Instrum., vol. 46, no. 2, 1997, pp. 454-458.

[13] Y.M. chang, S.I. kim, "Development of Clamp Current Meter using a Flexible Rogowski coil", Kieeme J. of Annual autumn conference, 2002, pp. 472-475. 


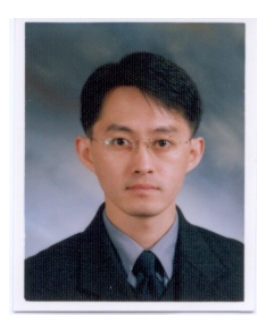

\section{Sung-chul Kim}

He received the M.S. degree in Electrical and Electronic Engineering from Sungkyunkwan University, Korea in 2001. He received the $\mathrm{Ph}$. D. degrees in Radiological science from Chonbuk National University in 2009. He is currently professor at Department of Radiological science of Gachon University. His research interests include x-ray equipment \& radiation detection. 